\title{
Three-Dimensional Foot Scanning System with a Rotational Laser-Based Measuring Head
}

\author{
Boštjan Novak ${ }^{1}$ - Aleš Babnik² - Janez Možina² - Matija Jezeršek2,* \\ ${ }^{1}$ Alpina d.o.o., Slovenia \\ 2University of Ljubljana, Faculty of Mechanical Engineering, Slovenia
}

\begin{abstract}
Three-dimensional (3D) measurements of the feet is crucial for the correct design and selection of shoes. Badly-fitting shoes are one of the major causes of pain, foot related diseases and injuries of the feet. This article presents a new system for 3D foot-shape measurements which is based on the laser-multiple-line-triangulation principle. The main part of a system is the measuring head comprising a three laser lines projection unit and two cameras, which rotate around the centre of the platform that the customer stands on, and measures both feet simultaneously. The developed software analyzes the different foot dimensions and suggests the most suitable model and size of a shoe from a database to the customer. Validation experiments have been presented to demonstrate the measuring precision of the system. The results show that the standard deviation for all feet dimensions is better than $0.6 \mathrm{~mm}$ in case of test objects.
\end{abstract}

Keywords: 3D foot measurement, laser-multiple-line-triangulation, foot dimensions, footwear fit

\section{INTRODUCTION}

Knowledge of the exact three-dimensional (3D) shape of the feet is extremely important for the footwear industry, since the correct fit between the shoe and the foot is an important comfort factor. Badly fitting shoes are the major cause of pain, foot related diseases and injuries [1] to [4]. 3D feet measurement therefore provides state of the art data for: (i) producing an adaptive design of a standard shoe; (ii) personalizing the shoe to individual foot dimensions; (iii) creating a better fitting for standard mass produced shoes and (iv) determining the best-fitting shoe for customers in a shop selling standard shoes. Traditionally, foot measuring techniques used callipers and measuring tapes. Simple mechanical devices were developed later, such as the Brannock device [5] and [6] or the Ritz stick length measuring device [7], which only measures a few of the most important foot dimensions, such as foot length, arch length and foot width. The next step in the foot measurement evolution are two-dimensional foot scanners, which measure the shape and dimensions of the footwear using a photo capturing in a flat plane [8]. The major drawback of these systems is the lack of foot height measurement. So-called two-and-half-dimension scanners, which measure foot contours from the top and side view [9] to [11] enable extraction of foot's length, width and height in any cross-section. But the girths of the crosssections, their curvature and local foot deformation are still not known.

The complete 3D scanning systems are the logical progression to the mentioned limitations of the earlier systems. These systems are mainly based on the laser triangulation principle. One of the first such systems was the measuring system made by the VORUM research corporation [12]. It has four laserline projectors and eight cameras, which measure the lateral cross-section of the foot, defined by the projected light plane. The entire $3 \mathrm{D}$ foot shape is further scanned by moving the complete projectorscameras assembly along the longitudinal foot axis (from the toes to the heel). Since the complexity of this system is relatively high due to the many cameras and lasers, which should be actuated during the measurement procedure, the price of the system is rather high. Similar system, but low cost, was later developed by Kouchi and Mochimaru [13]. Such systems are therefore mainly used in research and medical applications [14] to [17].

There are many attempts to overcome the economical drawback of above solution, which is still a gold standard in terms of measurement precision. One direction of development was to eliminate the scanning procedure. A representative of this technique is described in [18] where the foot is measured by four stationary measuring modules based on laser multiple line triangulation. The methods based on the fringe projection technique are also presented in [19] to [21]. The major improvement regarding the scanning techniques is the shorter measuring time, which in principle enables the study of the foot shape during walking [18] and [22] to [25].

The second line of development went into the reduction of the number of cameras and lasers. Such an example is the method described by Boer and Dulio [26]. The person being scanned steps on the platform, which has photogrammetric landmarks for the detection of the current position of the measuring head, consisting of a camera and lights. 
The measuring head rotates around the foot making a full circle and measures the 3D foot shape based on the stereo principle. The weak point of this solution is that prior to the measurement the subject needs to wear specially textured socks.

Foot scanning system presented in [27] is based on laser line triangulation where the measuring head moves around single foot in oval shaped trajectory. Again the measurement procedure consist of consecutive right and left foot scanning, where each takes approximately 13 seconds.

The new 3D foot measuring system represents an innovation in terms of simplification and speedup measurement. This is based on simultaneous measurement of both feet without using special socks. The apparatus is intended to be used mainly in shoe shops and in outpatient clinics; therefore its design is robust and simple to operate.

In the first part of this article an optomechatronic design based on the laser triangulation principle is described. Then the algorithms for a $3 \mathrm{D}$ shape reconstruction and the extraction of the dimensions of the feet are presented. The presentation is concluded with measurement examples which demonstrate the measuring precision of the system.

\section{OPTOMECHATRONIC DESIGN}

The 3D feet scanning system with a rotational measuring head is schematically presented in Fig. 1. The measuring head $(\mathrm{MH})$ is attached to the rotating arm (RA), which rotates around the centre of the standing platform (SP). The basic 3D measuring principle is laser-multiple-line triangulation [18] which is incorporated into a $\mathrm{MH}$. Since the $\mathrm{MH}$ measures only three profiles of the measured surface at a time, a rotational scanning technique is implemented to measure the entire surface of both feet simultaneously. The rotation of the RA and its marginal positions are also pointed out in Fig. 1a. The RA is driven by a stepper motor (SM) by using a synchro-belt transmission. The SM and the MH are controlled by the control unit (CU), which is connected to a personal computer (PC). The main part of the system is the $\mathrm{MH}$ which consists of a laser projection unit (LPU) and two cameras ( $\mathrm{C} 1$ and $\mathrm{C} 2)$ which are symmetrically positioned on each side of the LPU (see Fig. 2). The LPU projects three vertically directed and equally inclined laser light planes on the measured surface. The boundary laser light planes, LP-1 and LP1, are displaced for the interbeam angles $\delta_{1}$ and $\delta_{2}$ according to the central plane LP0, which is directed toward the centre of the SP.

Since the cameras acquire images of the illuminated measured surface from different viewpoints, the positions of the laser contour points in the image space are directly related to the distance between the $\mathrm{MH}$ and the measured points. The MH is positioned approximately $200 \mathrm{~mm}$ above the SP and is oriented towards the centre of the SP (see Fig. 1b). This position ensures that almost all the foot's surface area which is not in contact with the SP can be measured. It should be stressed that the sole part of a)

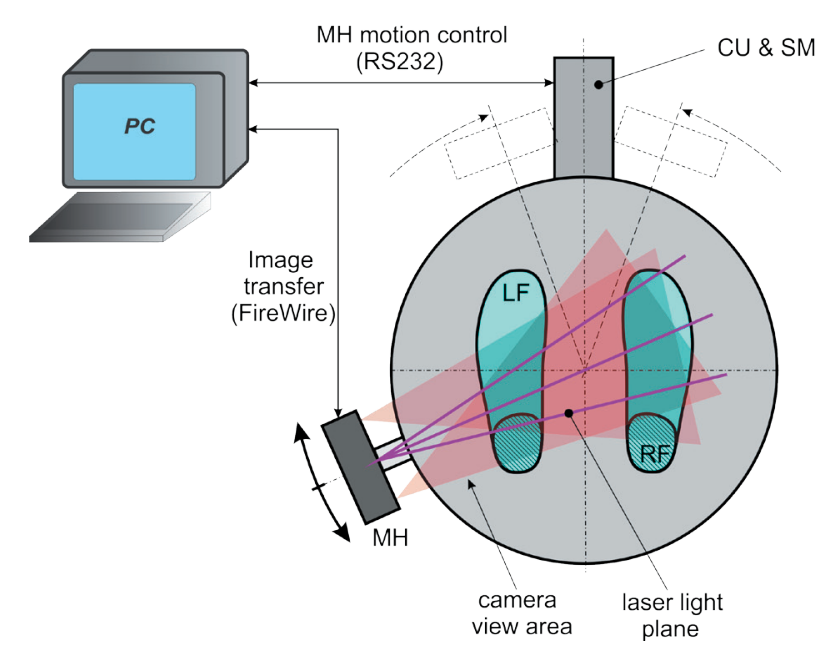

b)

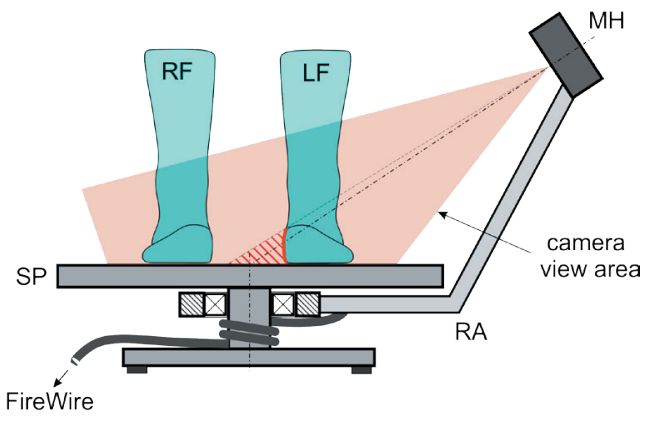

Fig. 1. Schematics of the $3 D$ foot scanning system with a rotational measuring head, a) top view, b) front view: $M H$ - measuring head , CU - control unit, SM - stepper motor drive, LF and RF - left and right measured foot, RA - rotating arm, SP - standing platform 
the foot, which is in contact with the SP has a planar shape and therefore its geometry is known.

The measuring head configuration with two cameras and three laser light planes was chosen to reduce the shadowing effects which appear on the inner sides of both feet. Figs. $3 \mathrm{a}$ and $\mathrm{b}$ show the situations where the $\mathrm{MH}$ is in a position where one camera $(\mathrm{C} 2$ in Fig. 3a or C1 in Fig. 3b) cannot see the illuminated surface of the opposite foot due to an occlusion with one of the ankles. So, two symmetrically positioned cameras are used to avoid these occlusions.

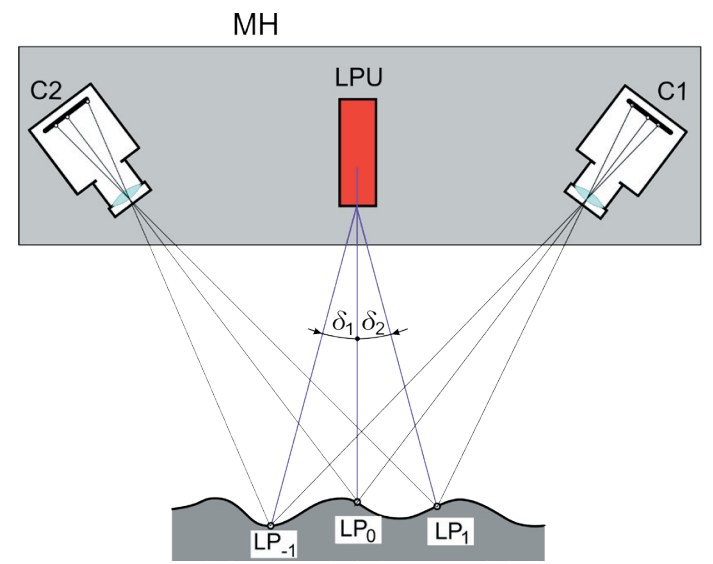

Fig. 2. Components of the measuring head - top view: C1 and C2 - two cameras, LPU - laser projection unit,

$$
L P_{-1} \text { to } L P_{1}-\text { laser light planes }
$$

The ankle also blocks the laser light planes from reaching the opposite foot (see Fig. 3c). Each light plane is blocked in a certain region (dashed areas on Fig. 3c) which is governed by the position and size of the ankle section and by the interbeam angles $\delta_{1}$ and $\delta_{2}$. We can see that by using only a central light plane LP0, the inner side of the toes are hidden (see the red dashed region in Fig. 3c). Therefore it is important that the regions where the light is blocked do not interfere. By using this rule, we can determine the position of the foot on the SP and the interbeam angles $\delta_{1}$ and $\delta_{2}$ so that the maximum length of the measured foot can be up to $325 \mathrm{~mm}$.

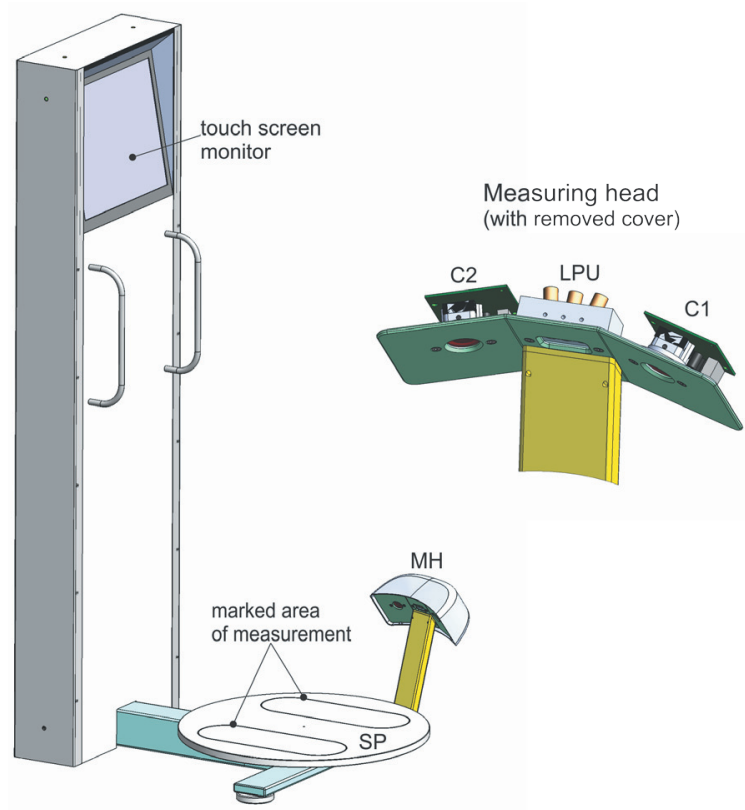

Fig. 4. Isometric view of the $3 D$ foot scanning system with the rotational measuring head

Fig. 4 shows the final design of the measuring system, which consists of two main subassemblies: the measuring part and the operating console. Both can be easily detached for long-distance transportation, but in case of room-to-room movement, the system has two wheels under the operating console. The cameras (producer: Unibrain; model: Fire-I; CCD sensor size: a)

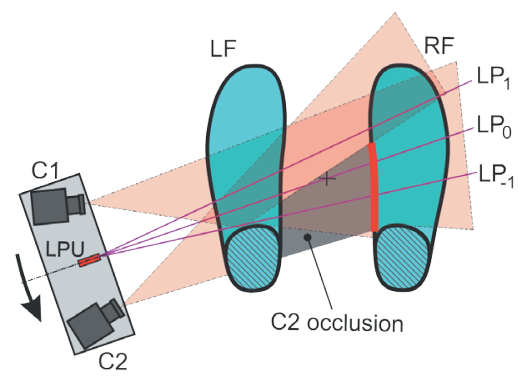

b)

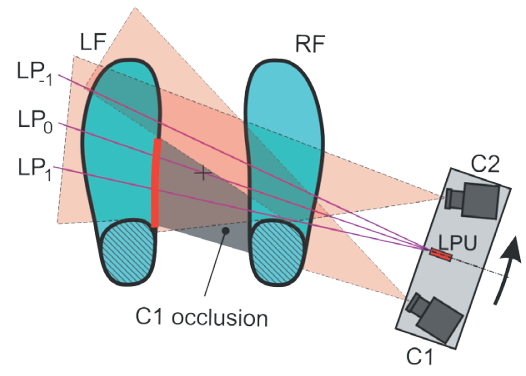

c)

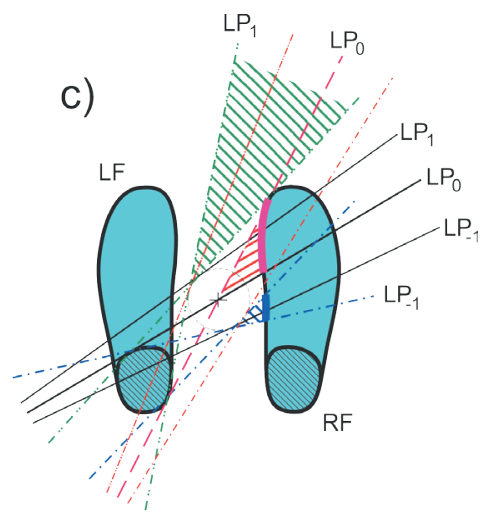

Fig. 3. Schematic presentation of the regions; a) and b) where the camera's views are obstructed and c) where the laser light planes are obstructed 
$1 / 4^{\prime \prime}, 640 \times 480$ pix), are attached symmetrically to the steel plate of the MH. The LPU consists of three laser line projectors (producer: World Star Tech.; model: FLL 5-3.5P-635-75). It is attached on the same plate in the middle position as is shown in Fig. 4c. The stepper motor drives the RA by using a synchro belt transmission with a reduction ratio of 20 . The CU is implemented with an 8 bit $\mu$ P PIC $16 f 876$ which drives the 4-poles unipolar SM and sends the data of the exact RA angular position for a single acquired camera-image to the PC. Communication between the $\mathrm{CU}$ and the PC is implemented by using the RS232. The PC (Asus Pundit P1-AH2) is the central unit for controlling the cameras, lasers and the rotation of the $\mathrm{MH}$. On the other hand, the PC stores the acquired images, extracts the 3D shapes and dimensions of the feet, calculates the fit between the feet and various footwear models and finally shows the results to the customer. A touch screen monitor (ELO 1715L 17") is used for a user-friendly interaction and measurement display.

\section{MEASURING PROCEDURE}

The measuring procedure starts when the customer steps on the SP and enters their gender and age. The measurement takes 10 seconds while the $\mathrm{MH}$ encircles both feet. During that time, the person must not move. After that the measured feet are reconstructed (see the next chapter) and shown in 3D together with the main dimensions, such as the length and maximum width, height and girth in the forefoot region. If the customer or operator is satisfied with the results, the complete $3 \mathrm{D}$ measurement is saved to the $\mathrm{PC}$, otherwise the measurement is repeated. If the system is used in a shoe shop then it follows the so called matching algorithm, where the geometrical difference between the foot and the shoe's internal volume is calculated for an entire assortment of selected shoe models [14], [26] and [28]. The models with the best fit are then suggested to the customer.

\section{DATA PROCESSING}

The data processing begins based on the images of the illuminated feet acquired by both cameras (see Fig. 5). The first processing step is a sub-pixel line detection [29], where the laser-line contours locations are determined along the vertical direction in each column of the image. Afterward, the correlation between the detected contours and the laser light planes is determined, which is done by sorting the segments along the vertical.

\subsection{Three-Dimensional Reconstruction}

The reconstruction of the 3D shape from the sequence of detected contours is performed in the next step. The algorithm is divided into partial transformations, where the first four are the same as described in [18]. Afterwards we get the coordinates of the measured point $\mathbf{T}$ in the $\mathrm{MH}$ coordinate system $\left(\mathrm{X}_{\mathrm{MH}}, \mathrm{Y}_{\mathrm{MH}}\right.$, $\mathrm{Z}_{\mathrm{MH}}$; see Fig. 6.), where the $\mathrm{Z}$ axis is collinear with the optical axis of the middle laser projector $\left(\mathrm{LP}_{0}\right)$, the origin is at the light planes' cross-section and the $\mathrm{X}$ axis is parallel with the camera's sensor plane as is shown in Fig. 6.
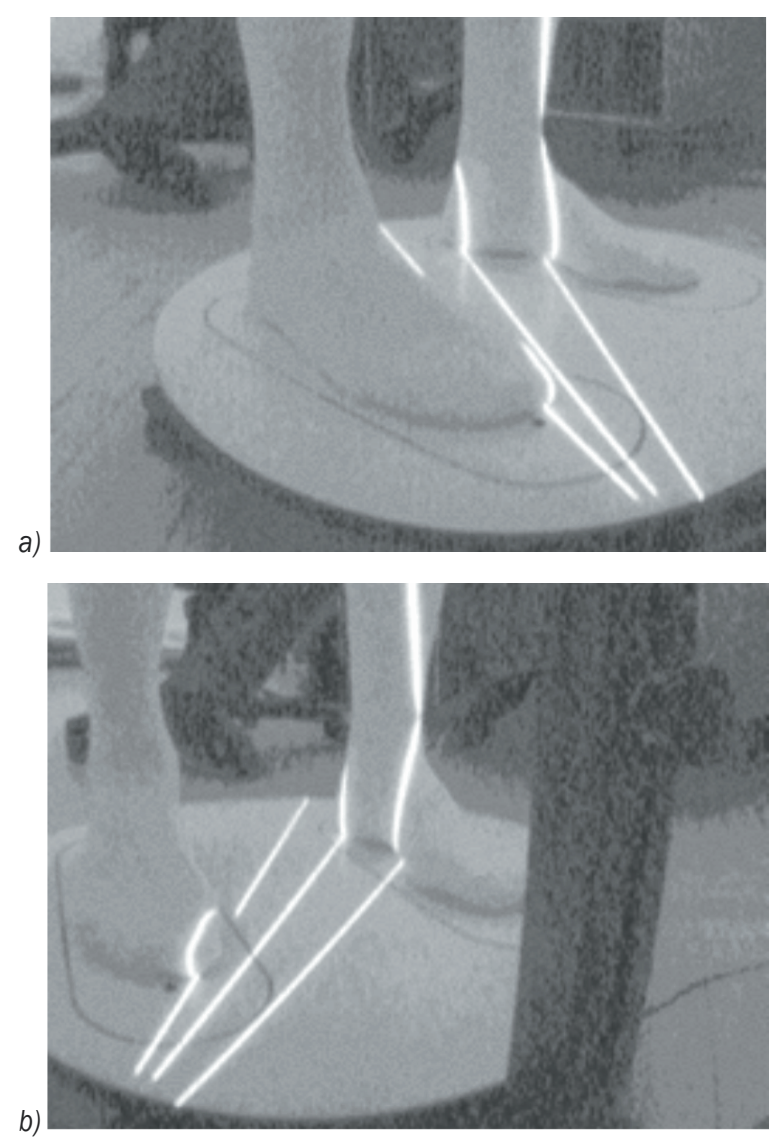

Fig. 5. Images of the illuminated feet and the standing platform acquired by cameras; a) $\mathrm{C} 1$, and b) $\mathrm{C} 2$

The transformation into the World Coordinate System (WCS) is the last step, which considers the rotation and translation of the MH. The WCS's XY plane lies on the SP, its origin is coincident with the centre of the SP and the $X_{\mathrm{W}}$ axis is directed toward to the operating console (see Fig. 6). By using such a convention, we can calculate the point radii vector $\left(\mathbf{r}_{\mathrm{W}}\right)$ by using the following equations: 


$$
\mathbf{r}_{\mathrm{W}}=\left(\left(\mathbf{R}_{\mathrm{MH}} \mathbf{r}_{\mathrm{MH}}-\mathbf{T}_{\mathrm{MH}}\right) \mathbf{R}_{\phi} \mathbf{R}_{\mathrm{SP}}\right)-\mathbf{T}_{\mathrm{W}},
$$

where $\mathbf{r}_{\mathrm{MH}}$ is the point radii vector described in the $\mathrm{MH}$ coordinate system and the rotation matrix $\mathbf{R}_{\mathrm{MH}}$ describes the rotation of the points around the $\mathrm{Z}_{\mathrm{MH}}$ and $\mathrm{Y}_{\mathrm{MH}}$ axis considering the $\beta$ and $\gamma$ angles respectively:

$$
\mathbf{R}_{\mathrm{MH}}=\left(\begin{array}{ccc}
\sin \beta \cos \gamma & \sin \gamma & \cos \beta \cos \gamma \\
-\sin \beta \sin \gamma & \cos \gamma & -\cos \beta \sin \gamma \\
-\cos \beta & 0 & \sin \beta
\end{array}\right) .
$$

Vector $\mathbf{T}_{\mathrm{MH}}$ describes the translation of the points for the distances $\mathrm{H}$ and $\mathrm{R}$ as shown in Fig. 7:

$$
\mathbf{T}_{\mathrm{MH}}=\left(\begin{array}{c}
\mathrm{R} \\
0 \\
\mathrm{H}
\end{array}\right) \text {. }
$$

The rotation matrix $\mathbf{R}_{\phi}$ considers the rotation of the $\mathrm{MH}$ around the rotation axis:

$$
\mathbf{R}_{\phi}=\left(\begin{array}{ccc}
\cos \phi & \sin \phi & 0 \\
-\sin \phi & \cos \phi & 0 \\
0 & 0 & 1
\end{array}\right),
$$

where $\phi$ is the angle between the $\mathrm{X}_{\mathrm{W}}$ axis and the rotation arm. The exact value of this angle is obtained from the CU during the scanning procedure for each acquired image. The last rotation matrix describes the deviation of the rotation axis from the perpendicular orientation relative to the SP (see Fig. 6):

$$
\mathbf{R}_{\mathrm{SP}}=\left(\begin{array}{ccc}
\sin \kappa & 0 & \cos \kappa \\
-\sin \kappa & \cos \varepsilon & -\cos \kappa \\
\sin \varepsilon & \sin \varepsilon & \cos \kappa
\end{array}\right),
$$

where $\varepsilon$ and $\kappa$ are the angles of inclination of the SP around the axes $X_{W}$ and $Y_{W}$ respectively. Finally, the points are translated for vector $\mathbf{T}_{\mathrm{W}}$, which describes the small misalignment between the calibration etalon and the origin of the rotation axis:

$$
\mathbf{T}_{\mathrm{W}}=\left(\begin{array}{c}
\Delta_{\mathrm{X}} \\
\Delta_{\mathrm{Y}} \\
0
\end{array}\right) .
$$

The misalignment in the $\mathrm{X}$ and $\mathrm{Y}$ direction is denoted by $\Delta_{\mathrm{X}}$ and $\Delta_{\mathrm{Y}}$, respectively.

The above-described calculation is performed for all the detected points of all three line segments and for all the acquired images from both cameras (typically 300 images from each camera). Since the basic laser triangulation arrangement consists of one camera, we treat our $\mathrm{MH}$ as an assembly of two measuring modules, where both use the same LPU. In this way we get six partially overlapping surfaces, where each surface belongs to one light plane measured by both cameras. An example of such measurement is shown in Fig. 7a, where the colours represent different surfaces. This kind of measurement is also called raw data, because post-processing steps must be done prior to extracting the dimensions of the feet.

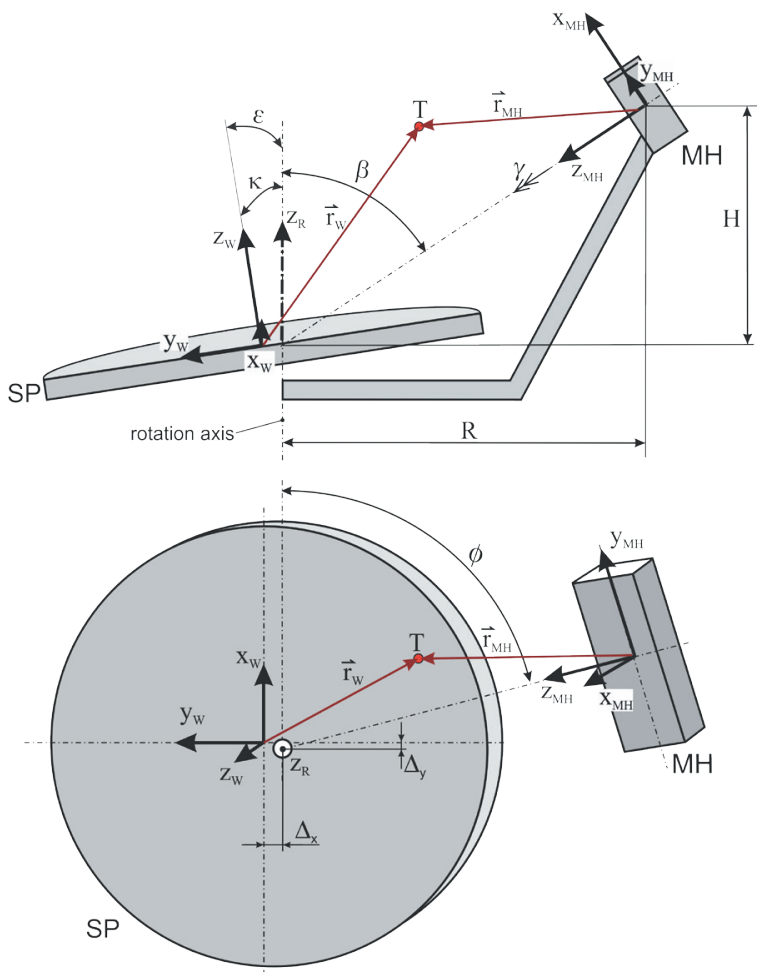

Fig. 6. Schematic representation of the measured point (T) transformation from the $\mathrm{MH}$ coordinate system to the World Coordinate System $\left(X_{W} Y_{W} Z_{W}\right)$

The first step is to create two groups, where the first includes all the points lying on the left hand side of the $\mathrm{X}_{\mathrm{W}} \mathrm{Z}_{\mathrm{W}}$ plane $\left(\mathrm{Y}_{\mathrm{W}}>0\right)$ and the second all other points. Cross-sections perpendicular to the $\mathrm{X}_{\mathrm{W}}$ axis are extracted at every millimetre in the second step. Each cross-section is further divided into the foot and supporting plate (SP) part. The points which describe the SP are then deleted, but the section where the foot is in contact with the SP is linearly interpolated. Fig. $7 \mathrm{~b}$ shows only point cloud of measured SP, where the sole contact area is clearly visible. Finally, the points between the consecutive cross-sections are triangulated, which results in two surfaces describing the left and right foot. These surfaces are then filtered by using a 3D filter where the radius of the averaging sphere is $3 \mathrm{~mm}$. An example of the post-processed measured feet is shown in Fig. 7c. 


\subsection{Extraction of Global Foot Dimensions}

Linear foot dimensions such as length, width, height and girth are also called global dimensions since they describe the foot as a whole. These dimensions are dependent on the measuring direction; therefore the first step in the extraction procedure is the alignment of the foot into a standard position, which is described in [18]. In such a position, the foot length is defined as a maximum $\mathrm{X}$ coordinate; the width is defined as the difference between the maximum and minimum $\mathrm{Y}$ coordinate of the cross-section at $66 \%$ of the foot length; and the height and girth are determined at the same cross-section. Besides the above-mentioned dimensions, the cross-sectional dimensions (width, height and girth) at other positions are also extracted to calculate the fit between the foot and shoe geometry.

\section{MEASUREMENT EXAMPLES}

To demonstrate the measuring precision of the system, three experiments were made: (i) measurements of test object to show the pure system dependent precision; (ii) measurements of living human to show the influence of foot deformability; and (iii) comparison between the traditional and 3D measurements according to ISO 20685 standard [30].

In the second case, none of the participants had before or at the time of measurement, injured or in any other way harmed their feet. The participants were informed of the methods used and their rights as participants. Written informed consent was obtained from all participants.

\subsection{Validation by a Test Object}

The plastic feet were copies of natural feet made from high density polyethylene. The length was 272.2 and $278.7 \mathrm{~mm}$ for the left and right foot respectively. Both feet were dressed in white cotton socks. They were positioned ten times randomly within the marked area of measurement (see Fig. 4) and measured. The measuring precision of the feet length $(L)$, width $(W)$ and girth $(G)$ were analysed by calculating the standard deviation (SD) of each dimension separately for the left and right foot. The results are shown in Table 1.

\subsection{Validation by a Living Human}

In the second step, the measurement repeatability of one male subject (age 48 years, height $1.70 \mathrm{~m}$, and weight $65 \mathrm{~kg}$ ) was studied. The subject wore white cotton socks on both feet. After each measurement, the subject had to step down from the SP and wait for 1 minute. An analysis of the measurements was made for the same dimensions as in the first step. The results for ten measurements are presented in Table 2 .

\subsection{Comparison between Traditional and 3D Measurements}

Twenty subjects (10 males and 10 females) of age $46.5 \pm 9$ years were measured using the presented system and traditionally using calliper and tape. Dimensions were then compared. Means, standard deviations and 95\% confidence intervals for $3 \mathrm{D}$ minus traditional measurements of length, width and girth are presented in Table 3. The 95\% confidence intervals were calculated as mean $\pm 1.96 \cdot \mathrm{SD}$.

Table 1. Results of the test object repeatability measurement. Plastic feet were measured 10 times

\begin{tabular}{|c|c|c|c|c|c|c|}
\hline & \multicolumn{3}{|c|}{ Left feet } & \multicolumn{3}{|c|}{ Right feet } \\
\hline & $\begin{array}{c}\text { Length } \\
{[\mathrm{mm}]}\end{array}$ & $\begin{array}{l}\text { Girth } \\
{[\mathrm{mm}]}\end{array}$ & $\begin{array}{l}\text { Width } \\
{[\mathrm{mm}]}\end{array}$ & $\begin{array}{c}\text { Length } \\
{[\mathrm{mm}]}\end{array}$ & $\begin{array}{c}\text { Girth } \\
{[\mathrm{mm}]}\end{array}$ & $\begin{array}{l}\text { Width } \\
{[\mathrm{mm}]}\end{array}$ \\
\hline MIN & 271.3 & 248.2 & 100.0 & 277.5 & 273.0 & 110.7 \\
\hline MAX & 273.1 & 249.7 & 101.2 & 279.4 & 275.1 & 112.3 \\
\hline MEAN & 272.2 & 248.9 & 100.4 & 278.7 & 274.4 & 111.8 \\
\hline SD & 0.6 & 0.5 & 0.4 & 0.6 & 0.6 & 0.5 \\
\hline
\end{tabular}
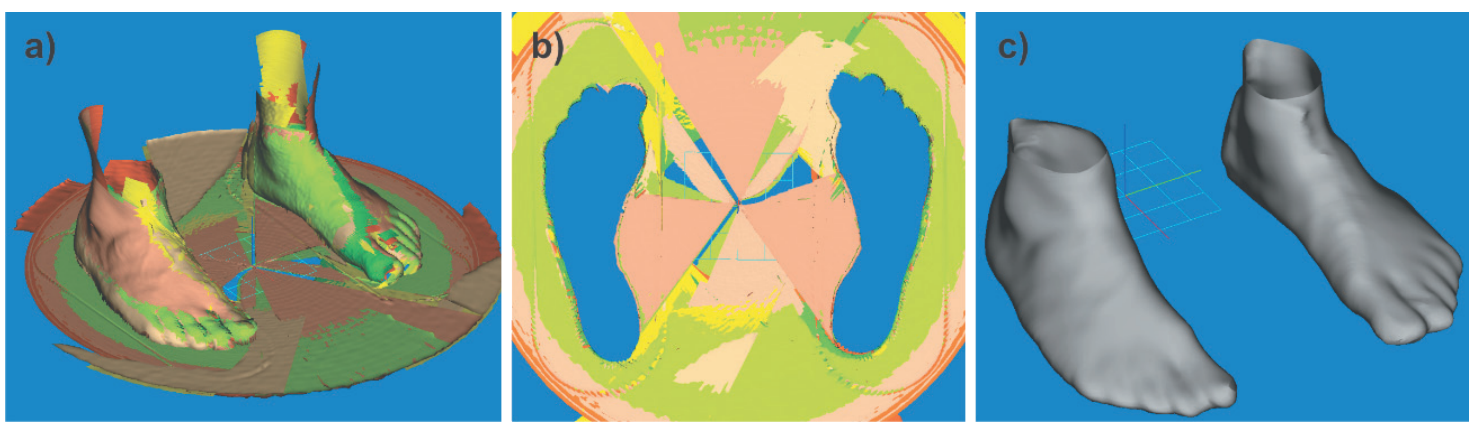

Fig. 7. Example of a) entire raw measured data, b) only raw data of measured supporting platform and c) the extracted feet 
Table 2. Results of the living human repeatability measurement. The subject was measured 10 times

\begin{tabular}{|c|c|c|c|c|c|c|}
\hline & \multicolumn{3}{|c|}{ Left feet } & \multicolumn{3}{|c|}{ Right feet } \\
\hline & $\begin{array}{c}\text { Length } \\
{[\mathrm{mm}]}\end{array}$ & $\begin{array}{c}\text { Girth } \\
{[\mathrm{mm}]}\end{array}$ & $\begin{array}{l}\text { Width } \\
{[\mathrm{mm}]}\end{array}$ & $\begin{array}{c}\text { Length } \\
{[\mathrm{mm}]}\end{array}$ & $\begin{array}{c}\text { Girth } \\
{[\mathrm{mm}]}\end{array}$ & $\begin{array}{l}\text { Width } \\
{[\mathrm{mm}]}\end{array}$ \\
\hline MIN & 274.1 & 252.8 & 104.9 & 270.6 & 253.2 & 104.7 \\
\hline MAX & 276.9 & 256.0 & 106.9 & 272.0 & 255.8 & 106.1 \\
\hline MEAN & 275.7 & 254.3 & 105.5 & 271.5 & 254.6 & 105.2 \\
\hline SD & 1.0 & 1.0 & 0.7 & 0.4 & 0.8 & 0.4 \\
\hline
\end{tabular}

Table 3. Comparison between traditionally and 3D measured feet dimensions; number of feet is 40; units are millimeters

\begin{tabular}{lcccc}
\hline & \multirow{2}{*}{$\begin{array}{c}\text { Mean } \\
\text { difference }\end{array}$} & $\begin{array}{c}\text { Standard } \\
\text { deviation }\end{array}$ & \multicolumn{2}{c}{ 95\% confidence limits } \\
\cline { 4 - 5 } & 1.3 & 0.7 & Lower & Upper \\
\hline Length & 1.3 & 0.1 & 2.7 \\
\hline Girth & 1.8 & 1.0 & 0.1 & 3.7 \\
\hline Width & 1.0 & 0.6 & 0.4 & 1.6 \\
\hline
\end{tabular}

\section{DISCUSSION}

The main objective of this paper is to show the operation principle and precision of the presented foot measuring system. Repeatability test of the plastic feet (presented in Table 1) shows that the SD for all feet dimensions is better than $0.6 \mathrm{~mm}$. The difference between the maximum and minimum foot length is 1.8 and $1.9 \mathrm{~mm}$ for the left and right foot respectively. The maximum difference for the width is 1.5 and $1.6 \mathrm{~mm}$, meanwhile the maximum difference of the girth is 1.5 and $2.1 \mathrm{~mm}$ for the left and right foot respectively. The comparison of the results between the left and right plastic feet does not show any essential difference.

The results of repeatability measurements of living human show (see Table 2) that the SD and maximum differences are approximately $60 \%$ higher compared with the plastic feet. The maximum SD corresponds to the length and girth of the left feet, which is $1.0 \mathrm{~mm}$. The maximum difference is in the girth measurement, where it is $3.2 \mathrm{~mm}$. The smallest difference and the SD correspond to the width, where the $\mathrm{SD}$ is $0.7 \mathrm{~mm}$ and the maximum difference is 2 $\mathrm{mm}$. We assume that the lower repeatability is mainly related to the transient fluctuations in feet dimensions, especially with a deformable foot, whose shape is mostly determined by the current pose of the subject [25].

Comparison between traditional and 3D measurement (see Table 3) shows that dimensions obtained by 3D measurement are systematically larger for $1.3,1.8$ and $1.0 \mathrm{~mm}$ in case of length, girth and width respectively. Further, the SD of differences are within the same range as SD obtained from repeatability measurements of living human.

According to ISO 20685 [30], the 3D foot scanning system can be said to give results sufficiently comparable to traditional methods if the $95 \%$ confidence interval for the 3D minus traditional measurements is within $\pm 2 \mathrm{~mm}$. Table 3 shows that only the width is measured with the sufficient accuracy, while the length and the girth measurements do not meet the requirement. The main reasons are large systematic offsets, which are more than three times greater than in case of test object (plastic feet). According to this we assume that the offsets originate mainly from the slight deformation of the live foot in the vicinity of the contact area during traditional measurement. In future software version this offset can be minimised with a simple calibration in order to provide compatible anthropometric data.

The presented results show that the measuring precision of the key foot-dimensions are better than the recommended precisions by Goonetilleke [31], therefore it can be concluded that the system is suitable for use in the footwear industry. The collected data are mainly used for: (i) automatic shoe size selection according to the customers feet and (ii) for development of new lasts. On the other hand, the system is not suitable for insole customization since it does not measure the entire sole area.

\section{CONCLUSION}

The presented system for 3D measuring of the foot is based on the laser-multiple-line triangulation principle. The main part of the system is the measuring head which rotates around the centre of the standing platform where the treated person stands and measures both feet simultaneously in 10 seconds. The analysis of the foot shape is performed for the length, width, height and girth. Three experiments were done to validate the measuring precision. Validation by plastic feet shows that the system measures the length, girth and width with a precision better than $0.6 \mathrm{~mm}$. Validation by living human shows that the repeatability is better than $1.0 \mathrm{~mm}$. Comparing with traditional measurements, dimensions are systematically larger for approximately $1.5 \mathrm{~mm}$ in case of 3D system. This is a consequence of foot deformation during traditional measurement.

The presented results show that the new system is versatile and yet affordable and easy to use tool for accurate feet measurement in footwear development [32], selling and research applications. At the moment a pilot production of 14 systems was already 
conducted, and the design is ready for industrial production.

\section{ACKNOWLEDGEMENT}

The research has been partly supported and financed by the European Union, European Social Fund, 2009.

\section{REFERENCES}

[1] Xiong, S., Zhao, J., Jiang, Z., Dong, M. (2010). A computer-aided design for foot-feature-based shoe last customization. International Journal of Advanced Manufacturing Technology, vol. 46, no. 1-4, p. 11-19, DOI:10.1007/s00170-009-2087-7.

[2] Mickle, K.J., Munro, B.J., Lord, S.R., Menz, H.B., Steele, J.R. (2010). Foot shape of older people: implications for shoe design. Footwear Science, vol. 2, no. 3, p. 131-139, DOI:10.1080/19424280.2010. 487053.

[3] Coughlin, M.J., Thompson, F.M. (1994). The high price of high-fashion footwear. The Journal of Bone and Joint Surgery, vol 76, no. 10, p. 1586-1593.

[4] Menz, H.B., Morris, M.E. (2005). Footwear characteristics and foot problems in older people. Gerontology, vol. 51, no. 5, p. 346-351, DOI:10.1159/000086373.

[5] The Brannock Device Co., Inc. (2013). The Brannock Device, from http://www.brannock.com/, accessed on 2013-07-01.

[6] Goonetilleke, R.S., Ho, E.E.H., So, R.H.Y. (1997). Foot sizing beyond the 2-D Brannock method. Annual Journal of the Institute of Industrial Engineers, Hong Kong, p. 28-31.

[7] Foot Measuring Devices (2013). Ritz Stick, from http:// www.footmeasure.com/ritz-stick, accessed on: 2013-0701.

[8] NVOS-Orhobanda (2002). Orthopedische shoentechniek. Boek 3 - maatnemen en Leesten (Orthopedic shoe technology. Book 3 - the Measurements and Lasts). NVOS-Orthobanda.

[9] Kolšek, T., Jurca, A., Vidič, T. (2011). Survey on parents' selection of children's footwear. Footwear Science, vol. 3, supplement no. 1, p. S88-D90, DOI:10. 1080/19424280.2011.575848.

[10] Lu, X., Jain, A.K., Colbry, D. (2006). Matching 2.5D face scans to 3D models. IEEE Transactions on Pattern Analysis and Machine Intelligence, vol. 28, no. 1, p. 31-43, DOI:10.1109/TPAMI.2006.15.

[11] Hajati, F., Raie, A.A., Gao, Y. (2012). 2.5D face recognition using patch geodesic moments. Pattern Recognition, vol. 45, no. 3, p. 969-982, DOI:10.1016/j. patcog.2011.08.025.

[12] Yeti TM. (2013). VORUM research coorporation, from http://www.vorum.com/english/footware/measurementcarving-yeti-3d-scanner.php, accessed on 2013-07-04.
[13] Kouchi, M., Mochimaru, M. (2001). Development of a low cost foot-scanner for a custom shoe making system. Proceedings of $5^{\text {th }}$ Symposium on Footwear Biomechanics, Zürich, p. 58-59.

[14] Witana, C.P., Feng, J., Goonetilleke, R.S. (2004). Dimensional differences for evaluating the quality of footwear fit. Ergonomics, vol. 47, no. 12, p. 1301-1317, DOI:10.1080/00140130410001712645.

[15] Xiong, S., Goonetilleke, R.S., Zhao, J., Li, W., Witana C.P. (2009). Foot deformations under different loadbearing conditions and their relationship to stature and body weight. Anthropological Science, vol. 117, no. 2, p 77-88, DOI:10.1537/ase.070915.

[16] Luximon, A., Goonetilleke, S.R., Zhang, M. (2005). 3D foot shape generation from 2D information. Ergonomics, vol. 48, no. 6, p. 625-641, DOI:10.1080/0014013050070970.

[17] Grimmer, R., Eskofier, B., Schlarb, H., Hornegger, J. (2011). Comparison and classification of 3D objects surface point clouds on the example of feet. Machine Vision and Applications, vol. 22, no. 2, p. 235-243, DOI:10.1007/s00138-009-0230-y.

[18] Jezeršek, M., Možina, J. (2009). High speed measurement of foot shape based on multiple-laserplane triangulation. Optical Engineering, vol. 48, no. 11, DOI:10.1117/1.3265522.

[19] Pan, J., Huang, P.S., Chiang, F.P. (2005). Color-coded binary fringe projection technique for 3-D shape measurement. Optical Engineering, vol. 44, no. 2, DOI:10.1117/1.1840973.

[20] Huang, P.S.S., Zhang, C.P., Chiang, F.P. (2003). Highspeed 3-D shape measurement based on digital fringe projection. Optical Engineering, vol. 42, no. 1, p. 163168, DOI:10.1117/1.1525272.

[21] Zhang, S., Huang, P.S. (2006). High-resolution, realtime three-dimensional shape measurement. Optical Engineering, vol. 45, no. 12, DOI:10.1117/1.2402128.

[22] Kouchi, M., Kimura, M., Mochimaru, M. (2009). Deformation of foot cross-section during walking. Gait \& Posture, vol. 30, no. 4. p. 482-486, DOI:10.1016/j. gaitpost.2009.07.113.

[23] Schmelzpfenning, T., Plank, C., Krauss, I., Aswendt, P., Grau, S. (2009). Dynamic foot scanning - A new approach for measurement of the human foot shape while walking. Footwear Science, vol. 1, suppl. 1, p. 28-30, DOI:10.1080/19424280902977111.

[24] Leardini, A., Benedetti, M.G., Berti, L., Bettinelli, D., Nativo, R., Giannini, S. (2007) Rear-foot, mid-foot and fore-foot motion during the stance phase of gait. Gait \& Posture, vol. 25, no. 3, p. 453-462, DOI:10.1016/j. gaitpost.2006.05.017.

[25] Novak, B., Možina, J., Jezeršek, M. (2014). 3D laser measurements of bare and shod feet during walking. Gait \& Posture, vol. 40, no. 1, p. 87,93, DOI:10.1016/j. gaitpost.2014.02.015.

[26] Boer, C.R., Dulio, S. (2007). Mass customization and footwear: Myth, Salvation or Reality, Springer Verlag London. 
[27] Fujita, H., Fukumoto, S., Yoshida, H., Wakasugi, Y., Kano, H. (2004). A 3D Foot Scanning System with a Sensor Head Guided around the Foot, from https:// www.jstage.jst.go.jp/article/iscie1988/17/8/17_8_330/ pdf, accessed on 2014-07-07.

[28] Nácher, B., Alemany, S., González, J.C., Alcántara, E., Garcia-Hernandes, J., Heras S., Juan A. (2006). A footwear fit classification model based on anthropometric data. SAE International Conference and Exposition of Digital Human Modeling for Design and Engineering, Lyon, SAE paper 2006-01-2356.
[29] Jezeršek, M., Možina, J. (2003). A laser anamorph profilometer. Strojniski vestnik - Journal of Mechanical Engineering, vol. 49, no. 2, p. 76-89.

[30] ISO 20685:2010. 3-D Scanning Methodologies for Internationally Compatible Anthropometric Databases, International Organization for Standardization, Geneva.

[31] Goonetilleke, R.S. (2013). The Science of Footwear. CRC Press - Taylor and Francis Group, Boca Raton.

[32] Mandić, V., Ćosić, P. (2011). Integrated product and process development in collaborative virtual engineering environment. Tehnički vjestnik - Technical Gazette, vol. 18, no. 3, p. 369-378. 